\title{
openheart Vitamin D levels and left ventricular diastolic function
}

\author{
Anil Pandit, ${ }^{1}$ Farouk Mookadam, ${ }^{1}$ Sailaja Boddu, ${ }^{1}$ Aashrayata Aryal Pandit, ${ }^{1}$ \\ Anwar Tandar, ${ }^{2}$ Hari Chaliki, ${ }^{1}$ Stephen Cha, ${ }^{3}$ Howard R Lee ${ }^{1}$
}

To cite: Pandit $A$, Mookadam F, Boddu S, et al. Vitamin D levels and left ventricular diastolic function. Open Heart 2014;1:e00011. doi:10.1136/openhrt-2013000011

Received 29 November 2013 Revised 21 January 2014 Accepted 28 January 2014

\section{CrossMark}

\footnotetext{
${ }^{1}$ Division of Cardiovascular Diseases, Mayo Clinic, Scottsdale, Arizona, USA ${ }^{2}$ Division of Cardiology, University of Utah, Salt Lake City, Utah, USA ${ }^{3}$ Division of Biomedical Informatics and Statistics, Mayo Clinic, Rochester, Minnesota, USA
}

Correspondence to Dr Howard R Lee; lee.howard@mayo.edu

\section{ABSTRACT}

Objective: To determine the association between serum vitamin D level and left ventricular (LV) diastolic dysfunction.

Background: Vitamin $D$ deficiency has been shown in observational and prospective studies to be associated with cardiovascular diseases including coronary artery disease, LV hypertrophy and systolic heart failure. Even though diastolic LV dysfunction is an early

manifestation of cardiac disease, there is no study that examines whether a deficiency of vitamin $D$ is associated with LV diastolic dysfunction.

Method: A retrospective observational review of 1011 patients (679 women) was conducted to examine if low 25- $\mathrm{OH}$-vitamin $\mathrm{D}$ levels were associated with LV diastolic dysfunction.

Results: All the LV diastolic dysfunction parameters: left atrial volume index, E/e', e' velocity, LV mass index and deceleration time were not significantly different between patients with $25-\mathrm{OH}$ vitamin $\mathrm{D}$ level $\leq 20 \mathrm{ng} / \mathrm{mL}$ vs $25-\mathrm{OH}$ vitamin D level $>20 \mathrm{ng} / \mathrm{mL}$.

Conclusions: Despite growing medical literature suggesting vitamin $D$ deficiency is associated with cardiovascular disease, in this present study there is no significant association of vitamin D levels and LV diastolic performance, including left atrial volume index.

\section{INTRODUCTION}

Vitamin D (Vit D) deficiency is highly prevalent and has been shown to be associated with cardiovascular diseases, including coronary artery disease, left ventricular (LV) hypertrophy and systolic heart failure. ${ }^{1-4}$ Vit D is an important hormone whose receptors are found in many tissues including cardiac myocytes ${ }^{5}$ and plays a significant role in the autocrine and paracrine regulation of cellular function, growth and differentiation in various organs. ${ }^{6}$ Although there is a substantial published literature on Vit D deficiency and cardiovascular diseases, ${ }^{7}$ there is a little data on Vit D deficiency and diastolic dysfunction or diastolic heart failure.

Since diastolic dysfunction is an early manifestation of LV hypertrophy and ventricular

\section{KEY MESSAGES}

Vitamin D deficiency is associated with various cardiovascular diseases.

- There is no study that examines whether deficiency of Vitamin D is associated with left ventricular diastolic dysfunction.

- The present study showed no significant association of Vitamin D levels and left ventricular diastolic performance, including left atrial volume index.

dysfunction, ${ }^{8}{ }^{9}$ it may reflect the effects of Vit D deficiency on the cardiovascular system. As a result, the present study examines if there is any association between Vit D levels and diastolic dysfunction as measured by comprehensive two-dimensional (2D) Doppler echocardiography.

\section{METHODOLOGY \\ Patient population}

A retrospective analysis of 1011 patients (679 women) from 2005 to 2010 who had an echocardiogram and a serum Vit D level performed. The Mayo Clinic Institutional Review Board approved the study. Patients were eligible if a 25-OH Vit D level was obtained within 1 month of a comprehensive echocardiogram. Patients were unselected and the specific reasons for obtaining Vit D levels and echocardiographic examination were not evaluated. In 20 patients, Vit D levels were reported as $<6 \mathrm{ng} / \mathrm{mL}$; these values were recorded as $6 \mathrm{ng} / \mathrm{mL}$ while performing statistical analysis. The patients were divided into two groups: group 1 with serum Vit D level $\leq 20 \mathrm{ng} / \mathrm{mL}$ and group 2 with serum Vit D level $>20 \mathrm{ng} / \mathrm{mL}$. This classification of Vit D levels was in part based on the recommendations of the 2011 Institute of Medicine report. ${ }^{10}$ Vit D levels were measured by liquid chromatography-tandem mass spectrometry on the Roche Cobas systems. We also run parathyroid hormone, pro-brain 
natriuretic peptide (BNP), total prostate-specific antigen and thyroid stimulating hormone on Cobas 601 All demographic, clinical and echocardiographic measurements pertaining to LV diastolic function were compared between the two groups.

Patients with significant valvular disease ( $>$ moderate regurgitation or stenosis), LV ejection fraction $(\mathrm{EF})<$ $50 \%$, atrial fibrillation or serum creatinine $>2 . \mathrm{mg} / \mathrm{dL}$ were excluded from the study. Definition of abnormal diastolic dysfunction was based on the American and European Society of Echocardiography criteria grading system. ${ }^{11} 12$ Patient demographics and conventional cardiovascular risk factors of hypertension, diabetes, smoking history and clinical coronary artery disease presence were included in the analysis.

\section{Echocardiography}

Each participant underwent detailed transthoracic2D, and tissue Doppler imaging echocardiography performed with a GE instrument (GE Healthcare, Milwaukee, Wisconsin, USA) by standard techniques as described earlier, with participants in the left lateral decubitus position. Echocardiograms were uploaded digitally to an online system (ProSolv CardioVascular, Indianapolis, Indiana, USA) for measurement and analysis. Echocardiograms were interpreted by American Society of Echocardiography board certified echocardiologists.

Echocardiographic measurements performed according to the American Society of Echocardiography guidelines included left atrial volume (LAV), using the area length method indexed to body surface area; EF was measured using volumetric biplane Simpson method, LV mass index (LVMI) and diastolic parameters (E, A, deceleration time (DT), E/A ratio and E/e').

\section{Measurements of diastolic function}

Mitral inflow

Pulsed wave Doppler was performed in apical fourchamber view to obtain mitral inflow velocities. $1-3 \mathrm{~mm}$ sample volume was placed between mitral valve leaflet tips during diastole to record a crisp mitral velocity profile.

\section{Tissue Doppler annular velocities}

Pulsed wave Doppler imaging was performed in apical views to obtain tissue Doppler annular velocities. The sample volume was placed at or $1 \mathrm{~cm}$ within the septal insertion sites of the mitral leaflets and adjusted as necessary to cover the longitudinal excursion of mitral annulus in systole and diastole.

\section{Statistical analysis}

The data were summarised as means and SD for continuous variables. Using $t$ test compared the means of echocardiographic continuous variables and Vit D levels among the groups. When means were compared between more than two groups, one-way analysis of variance test was used. Categorical variables were compared with $\chi^{2}$ test. Any $\mathrm{p}$ value of less than 0.05 was considered statistically significant. We also performed simple regression between echocardiographic parameters and Vit D level. Since age, hypertension and concomitant Vit D therapy was different among the groups compared, we performed regression analysis adjusted for age,

Table 1 Demographics and clinical variables between groups 1 and 2

\begin{tabular}{|c|c|c|c|c|c|c|c|}
\hline Variable & \multicolumn{2}{|l|}{ Overall } & \multicolumn{2}{|c|}{$\begin{array}{l}\text { Group } 1 \\
\text { (Vit } D \leq 20 \mathrm{ng} / \mathrm{mL} \text { ) }\end{array}$} & \multicolumn{2}{|c|}{$\begin{array}{l}\text { Group } 2 \\
\text { (Vit } D>20 \mathrm{ng} / \mathrm{mL} \text { ) }\end{array}$} & p Value \\
\hline Age & 61.16 & \pm 16.43 & 56.95 & \pm 15.70 & 62.22 & \pm 16.45 & $<0.001$ \\
\hline Female, $\mathrm{n}=679$ & & & 131 & $64 \%$ & 548 & $68 \%$ & 0.32 \\
\hline 25-OH Vit D, ng/mL & 31.37 & \pm 15.59 & 13.38 & \pm 4.57 & 35.92 & \pm 14.03 & $<0.001$ \\
\hline $\mathrm{BMI}$ & 27.18 & \pm 6.81 & 28.47 & \pm 8.42 & 26.86 & \pm 6.31 & 0.003 \\
\hline $\mathrm{Ca}^{2+}, \mathrm{mg} / \mathrm{dL}$ & 9.5 & \pm 2.76 & 8.96 & \pm 0.84 & 9.64 & \pm 3.05 & 0.002 \\
\hline Creatinine, $\mathrm{mg} / \mathrm{dL}$ & 0.94 & \pm 0.65 & 0.92 & \pm 0.77 & 0.95 & \pm 0.61 & 0.61 \\
\hline HTN, n (\%) & 471 & 47 & 85 & 42 & 386 & 48 & 0.11 \\
\hline $\mathrm{DM}, \mathrm{n}(\%)$ & 137 & 14 & 44 & 22 & 93 & 12 & $<0.001$ \\
\hline CAD, n (\%) & 115 & 11 & 22 & 11 & 93 & 12 & 0.77 \\
\hline Smoking, n (\%) & 71 & 7 & 24 & 12 & 47 & 6 & 0.003 \\
\hline Enlarged LA, n (\%) & 492 & 48 & 90 & 44 & 402 & 49.8 & 0.5 \\
\hline \multicolumn{8}{|l|}{ Grade, n (\%) } \\
\hline 0 & 508 & 50 & 117 & 57 & 391 & 49 & 0.34 \\
\hline 1 & 246 & 24 & 44 & 22 & 202 & 25 & \\
\hline $1 a$ & 154 & 15 & 25 & 12 & 129 & 16 & \\
\hline 2 & 92 & 9 & 17 & 8 & 75 & 9 & \\
\hline 3 & 9 & 1 & 1 & 0 & 6 & 1 & \\
\hline Vit D Rx & & & \multicolumn{2}{|c|}{$42 / 191(22 \%)$} & \multicolumn{2}{|c|}{$273 / 786(34.73 \%)$} & 0.0007 \\
\hline
\end{tabular}

BMI, body mass index; CAD, coronary artery disease; DM, diabetes mellitus; HTN, hypertension; LA, left atrium; Enlarged LA, LA volume index of greater than 28.9; $n$, sample size; Vit $D$, vitamin $D$. 
Table 2 Comparison of echocardiographic parameters between groups 1 and 2

\begin{tabular}{|c|c|c|c|c|c|c|c|}
\hline \multirow[b]{2}{*}{ Variable } & \multirow{2}{*}{\multicolumn{2}{|c|}{$\frac{\text { Overall }}{(\mathrm{N}=1011)}$}} & \multirow{2}{*}{\multicolumn{2}{|c|}{$\frac{\text { Group } 1 \text { (Vit } D \leq 20)}{(\mathrm{N}=204)}$}} & \multicolumn{2}{|c|}{ Group 2 (Vit D > 20) } & \multirow[b]{2}{*}{ p Value } \\
\hline & & & & & $(\mathrm{N}=807)$ & & \\
\hline EF & 64.22 & \pm 5.93 & 64.29 & \pm 6.62 & 64.2 & \pm 5.74 & 0.84 \\
\hline IVS, mm & 10.84 & \pm 4.72 & 11.49 & \pm 9.72 & 10.68 & \pm 2.08 & 0.03 \\
\hline LV mass index & 89.27 & \pm 25.34 & 91.43 & \pm 28.14 & 88.74 & \pm 24.59 & 0.19 \\
\hline LVEDD, mm & 44.91 & \pm 5.30 & 45.16 & \pm 5.69 & 44.85 & \pm 5.20 & 0.46 \\
\hline LAVI & 30.35 & \pm 10.62 & 30.05 & \pm 9.72 & 30.42 & \pm 10.83 & 0.67 \\
\hline$E / A$ & 1.13 & \pm 0.48 & 1.14 & \pm 0.46 & 1.13 & \pm 0.48 & 0.99 \\
\hline DT & 213.77 & \pm 53.54 & 213.02 & \pm 63.90 & 213.95 & \pm 50.73 & 0.83 \\
\hline$e^{\prime}$ & 0.08 & \pm 0.05 & 0.08 & \pm 0.03 & 0.08 & \pm 0.06 & 0.92 \\
\hline$E / e^{\prime}$ & 11.34 & \pm 5.55 & 11.3 & \pm 5.35 & 11.35 & \pm 5.61 & 0.91 \\
\hline
\end{tabular}

hypertension and Vit D therapy for Vit D level and echocardiographic parameters.

\section{RESULTS}

The study population $(n=1011)$ is described in table 1 . Group 1 patients were younger, had a higher BMI, were more likely diabetics and/or smokers and had lower serum calcium levels, although still in the normal range. Women comprised $67 \%$ of the entire cohort without a significant difference between groups 1 and 2. The mean Vit D level of the entire cohort was $31.4 \pm 15.6 \mathrm{ng} / \mathrm{mL}$.

\section{Morphological measurements}

Overall mean LVMI was $89.27 \pm 25.34$ in the entire cohort. There was no statistically significant difference between groups 1 and 2 (91.43 \pm 28.14 vs $88.74 \pm 24.59$, $\mathrm{p}=0.19$; table 2). LV size measured as mean LV end diastolic dimension was $44.91 \pm 5.30 \mathrm{~mm}$ in the entire cohort. Groups 1 and2 (45.16 \pm 5.69 vs $44.85 \pm 5.20 \mathrm{~mm}$ $\mathrm{p}=0.46$ ) were not statistically different in diameter size (table 2). Mean LA volume index (LAVI) was 30.35 \pm 10.6 in the entire cohort. There was no statistically significant difference in mean between groups 1 and $2(30.05 \pm 9.7$ vs $30.42 \pm 10.8, \mathrm{p}=0.67$; table 2 ). Only measurement found to be significant between the groups was interventricular septal thickness $(11.49 \pm 9.72$ vs $10.68 \pm 2.08 \mathrm{~mm}$, $\mathrm{p}=0.03$ ). Linear regression did not show any definite trend of Vit D versus LAVI (data not shown).

\section{Doppler measurements}

The mean $\mathrm{E} / \mathrm{A}$ ratio was $1.13 \pm 0.48$ in the entire cohort, without a statistically significant difference between groups land 2 ( $1.14 \pm 0.46$ vs $1.13 \pm 0.48, \mathrm{p}=0.99$; table 2$)$. Similarly, the mean DT was $213.77 \pm 53.54$ ms. There were no statistically significant difference between groups 1 and 2 (213.02 \pm 63.9 vs $213.95 \pm 50.73 \mathrm{~ms}, \mathrm{p}=0.83)$. The mean tissue Doppler parameter, e' velocity was normal at $0.08 \pm 0.05$ $\mathrm{m} / \mathrm{s}$ in the entire cohort. There was no statistically significant difference between groups 1 and $2(0.08 \pm 0.03$ vs 0.08 $\pm 0.06 \mathrm{~m} / \mathrm{s}, \mathrm{p}=0.92)$. As a surrogate of $\mathrm{LV}$ filling pressures, mean E/e' was $11.34 \pm 5.55$ in the entire cohort, without a statistically significant difference between groups land 2 $(11.3 \pm 5.35$ vs $11.35 \pm 5.61, p=0.91)$. We did not find any association between Vit D level and any echocardiographic parameters of LV diastolic dysfunction after adjusting for age, hypertension and concomitant Vit D therapy (table 3). Since Vit D level of $<20 \mathrm{ng} / \mathrm{mL}$ is not recognised widely as Vit D deficiency threshold, we reanalysed our data based on Vit D level of $<10,10-30$ and $>30 \mathrm{ng} / \mathrm{mL}$. With this grouping we did find that Vit D level $>30 \mathrm{ng} / \mathrm{mL}$ was associated with higher $\mathrm{E} / \mathrm{e}$ ' but there was no difference in number of abnormal diastology grade in this group compared with $<10$ and $10-30 \mathrm{ng} / \mathrm{mL}$ as shown in table 4 . We further classified our data based on $\mathrm{E} / \mathrm{e}$ ' ratio of $<8,8-14$ and $>14$. We did not find any difference in mean Vit D levels in these groups too as shown in table 5.

\section{DISCUSSION}

The main finding of this study is that Vit D levels measured in a temporal relationship to a comprehensive

Table 3 Regression analysis by Vit D level

\begin{tabular}{|c|c|c|c|c|}
\hline \multirow[b]{2}{*}{ Variable } & \multicolumn{2}{|c|}{ Unadjusted } & \multicolumn{2}{|c|}{$\begin{array}{l}\text { Adjusted by age, } \\
\text { HTN Rx }\end{array}$} \\
\hline & Estimate & p Value & Estimate & p Value \\
\hline EF & 0.00333 & 0.7806 & 0.00427 & 0.7275 \\
\hline IVS & -0.01443 & 0.1324 & -0.00981 & 0.0133 \\
\hline Mass & -0.07576 & 0.1423 & -0.12261 & 0.0149 \\
\hline LVEDD & -0.02131 & 0.0477 & -0.01541 & 0.1638 \\
\hline LA Vol & -0.00516 & 0.8136 & -0.03452 & 0.1015 \\
\hline$E / A$ & -0.00102 & 0.3003 & 0.00075 & 0.3784 \\
\hline$e^{\prime}$ & -0.00005 & 0.6172 & 0.00005 & 0.6635 \\
\hline E/e' & 0.00765 & 0.4996 & -0.00922 & 0.3684 \\
\hline
\end{tabular}

$\mathrm{A}$, late mitral diastolic flow velocity; $\mathrm{E}$, early mitral diastolic flow velocity; e', early diastolic mitral annular velocity; EF, ejection fraction; HTN, hypertension; IVS, interventricular septum; LAVI, left atrial volume index; LV, left ventricular; LVEDD, left ventricular end diastolic dimension. 
Table 4 Reclassification of demographic and echocardiographic data based on Vit D level of $<10,10-30 \mathrm{and}>30 \mathrm{ng} / \mathrm{mL}$

\begin{tabular}{|c|c|c|c|c|c|c|c|c|c|}
\hline \multirow{2}{*}{$\frac{\text { Variable }}{\text { Age }}$} & \multicolumn{2}{|c|}{$\begin{array}{l}\text { Overall } \\
(\mathrm{N}=1011)\end{array}$} & \multicolumn{2}{|l|}{$\begin{array}{l}<10 \\
(\mathrm{~N}=56)\end{array}$} & \multicolumn{2}{|c|}{$\frac{\text { Vit D 10-30 }}{(\mathrm{N}=457)}$} & \multicolumn{2}{|c|}{$\begin{array}{l}>30 \\
(\mathrm{~N}=498)\end{array}$} & p Value \\
\hline & 61.16 & \pm 16.43 & 51.41 & \pm 14.01 & 60.42 & \pm 16.29 & 62.93 & \pm 16.40 & $<0.001$ \\
\hline Sex, n (\%) & & & & & & & & & 0.019 \\
\hline Male & 332 & 33 & 16 & 29 & 171 & 37 & 145 & 29 & \\
\hline Female & 679 & 67 & 40 & 71 & 286 & 63 & 353 & 71 & \\
\hline HTN, n (\%) & 471 & 47 & 19 & 34 & 200 & 44 & 252 & 51 & 0.018 \\
\hline DM, n (\%) & 137 & 14 & 13 & 23 & 73 & 16 & 51 & 10 & 0.003 \\
\hline CAD, n (\%) & 115 & 11 & 3 & 5 & 57 & 13 & 55 & 11 & 0.26 \\
\hline Smoke, n (\%) & 71 & 7 & 9 & 16 & 40 & 9 & 22 & 4 & $<0.001$ \\
\hline D grade, n (\%) & & & & & & & & & 0.21 \\
\hline 0 & 508 & 59 & 41 & 76 & 225 & 58 & 242 & 59 & \\
\hline 1 & 246 & 29 & 10 & 19 & 116 & 30 & 120 & 29 & \\
\hline $1 \mathrm{a}$ & 154 & 15 & 7 & 13 & 62 & 14 & 85 & 17 & \\
\hline 2 & 92 & 11 & 3 & 6 & 41 & 11 & 48 & 12 & \\
\hline 3 & 9 & 1 & 0 & 0 & 7 & 2 & 2 & 0 & \\
\hline Vit D Rx & & & $8 / 51(8$ & & $120 / 436$ & $7.5 \%)$ & $187 / 490$ & $3.16 \%)$ & 0.0001 \\
\hline 25 Vit D, ng/mL & 31.37 & \pm 15.59 & 7.28 & \pm 1.34 & 22.68 & \pm 5.60 & 42.05 & \pm 14.70 & $<0.001$ \\
\hline $\mathrm{Ca}++$ & 9.5 & \pm 2.76 & 8.54 & \pm 0.82 & 9.32 & \pm 0.71 & 9.79 & \pm 3.84 & 0.6 \\
\hline $\mathrm{Cr}$ & 0.94 & \pm 0.65 & 1.07 & \pm 1.37 & 0.9 & \pm 0.57 & 0.96 & \pm 0.58 & 0.12 \\
\hline EF & 64.22 & \pm 5.93 & 66.3 & \pm 6.98 & 63.97 & \pm 5.99 & 64.21 & \pm 5.71 & 0.021 \\
\hline IVS & 10.84 & \pm 4.72 & 10.52 & \pm 2.14 & 11.07 & \pm 6.64 & 10.66 & \pm 2.09 & 0.36 \\
\hline Mass & 89.27 & \pm 25.34 & 86.89 & \pm 28.76 & 89.94 & \pm 25.86 & 88.94 & \pm 24.46 & 0.65 \\
\hline LVEDD & 44.91 & \pm 5.30 & 44.37 & \pm 6.37 & 45.34 & \pm 5.48 & 44.58 & \pm 4.97 & 0.07 \\
\hline LA Vol & 30.35 & \pm 10.62 & 28.41 & \pm 8.52 & 30.25 & \pm 10.21 & 30.64 & \pm 11.16 & 0.36 \\
\hline$E / A$ & 1.13 & \pm 0.48 & 1.04 & \pm 0.33 & 1.16 & \pm 0.49 & 1.12 & \pm 0.48 & 0.13 \\
\hline DT & 213.77 & \pm 53.54 & 199.4 & \pm 38.71 & 215.3 & \pm 57.81 & 213.73 & \pm 50.50 & 0.16 \\
\hline$e^{\prime}$ & 0.08 & \pm 0.05 & 0.09 & \pm 0.03 & 0.08 & \pm 0.06 & 0.08 & \pm 0.05 & 0.19 \\
\hline E/e' & 11.34 & \pm 5.55 & 9.39 & \pm 3.39 & 11.52 & \pm 5.79 & 11.39 & \pm 5.49 & 0.029 \\
\hline RVSP & 31.89 & \pm 9.70 & 33.54 & \pm 11.87 & 31.96 & \pm 9.36 & 31.67 & \pm 9.77 & 0.51 \\
\hline
\end{tabular}

$\mathrm{A}$, late mitral diastolic flow velocity; BMI, body mass index; CAD, coronary artery disease, DM, diabetes mellitus; DT, deceleration time of mitral E wave; E, early mitral diastolic flow velocity; e', early diastolic mitral annular velocity; EF, ejection fraction; HTN, hypertension,

IVS, interventricular septum; LA, left atrium; LAVI, left atrial volume index; LV, left ventricular; LVEDD, left ventricular end diastolic dimension; $\mathrm{n}$, sample size; RVSP, right ventricular systolic pressure; Vit D, vitamin D.

diagnostic echocardiogram with detailed examination of LV diastolic function showed no significant correlation with diastolic function. To the best of our knowledge this is the first, large cross-sectional study attempting to examine any relationship between baseline Vit D levels and comprehensive echocardiography to study LV diastolic function. Vit D therapy has been reported to be associated with the reduction of LAV index and attenuation of a rise of $\mathrm{BNP}$ in patients with chronic kidney disease with mild-to-moderate LV hypertrophy. ${ }^{13}$ Recently, the Hoorn study $^{14}$ showed in a prospective manner that Vit D levels at baseline were not associated with LAVI over a subsequent 8 years of follow-up. In addition, the lowest Vit D quartile had a significantly higher LVMI than the highest quartile. These results were attenuated by multivariable analysis. Of note, the Hoorn study did not measure other diastolic parameters including tissue doppler measurements.

Our cohort involved patients with hypertension and diabetes, both of which can influence LV mass and diastolic function. ${ }^{15}$ The National Health and Nutrition Examination Survey has demonstrated that almost half of the US population has at least one of three diagnosed or undiagnosed conditions; hypertenion, diabetes or hyperlipidaemia. If we had excluded diabetes and hypertension, then a major proportion of patients would have been excluded from the study limiting generalisability of our results. Other large studies have also included patients with these conditions at baseline. ${ }^{4}{ }^{7}$ In our study with a large cohort of about 1000 patients, a statistically significant number of patients with diabetes were represented in Vit D deficiency group. However, it is very interesting to note that despite a higher proportion of patients with diabetics in group 1, none of diastolic parameters including LAVI (a surrogate marker of longterm diastolic dysfunction) were different between the study groups. Our cohort also included patients with hypertension which is a well-known factor influencing both LV mass and diastolic dysfunction. However, the proportion of hypertensive patients in both study groups were not different (group 1, 85/204 vs group 2, 386/ 807, t-test, $\mathrm{p}=0.11)$. It is also interesting to note that patients with a higher Vit D level were likely to be on Vit $\mathrm{D}$ replacement therapy and women, however, it did not 
Table 5 Reclassification of entire data set based on E/e' thresholds of $<8,8-14$ and $>14$

\begin{tabular}{|c|c|c|c|c|c|c|c|c|c|}
\hline \multirow{2}{*}{$\frac{\text { Variable }}{\text { Age }}$} & \multicolumn{2}{|c|}{$\frac{\text { Overall }}{(\mathrm{N}=1011)}$} & \multicolumn{2}{|c|}{$\frac{<8}{(\mathrm{~N}=256)}$} & \multicolumn{2}{|c|}{$\frac{E / e^{\prime} 8-14}{(N=537)}$} & \multicolumn{2}{|c|}{$\frac{15+}{(N=185)}$} & p Value \\
\hline & 61.16 & \pm 16.43 & 49.73 & \pm 16.49 & 62.51 & \pm 14.30 & 72.65 & \pm 11.83 & $<0.001$ \\
\hline Sex, n (\%) & & & & & & & & & 0.07 \\
\hline Male & 332 & 33 & 81 & 32 & 188 & 35 & 48 & 26 & \\
\hline Female & 679 & 67 & 175 & 68 & 349 & 65 & 137 & 74 & \\
\hline HTN, n (\%) & 471 & 47 & 72 & 28 & 263 & 49 & 119 & 65 & $<0.001$ \\
\hline DM, n (\%) & 137 & 14 & 22 & 9 & 67 & 13 & 46 & 25 & $<0.001$ \\
\hline CAD, n (\%) & 115 & 11 & 16 & 6 & 61 & 11 & 34 & 18 & $<0.001$ \\
\hline Smoke, n (\%) & 71 & 7 & 20 & 8 & 38 & 7 & 10 & 5 & 0.61 \\
\hline $\mathrm{D}$ grade, $\mathrm{n}(\%)$ & & & & & & & & & $<0.001$ \\
\hline 0 & 508 & 59 & 194 & 78 & 257 & 56 & 36 & 31 & \\
\hline 1 & 246 & 29 & 50 & 20 & 176 & 38 & 12 & 10 & \\
\hline $1 \mathrm{a}$ & 154 & 15 & 32 & 13 & 88 & 16 & 30 & 16 & \\
\hline 2 & 92 & 11 & 3 & 1 & 26 & 6 & 61 & 53 & \\
\hline 3 & 9 & 1 & 1 & 0 & 1 & 0 & 7 & 4 & \\
\hline Vit D Rx & & & $68 / 249$ & & $161 / 523$ & $0.8 \%)$ & $75 / 178$ & $1 \%)$ & 0.0036 \\
\hline 25 Vit D, ng/mL & 31.37 & \pm 15.59 & 31.1 & \pm 14.89 & 31.45 & \pm 16.64 & 32.15 & \pm 13.88 & 0.78 \\
\hline $\mathrm{Ca}^{2+}$ & 9.5 & \pm 2.76 & 9.37 & \pm 0.66 & 9.45 & \pm 0.72 & 9.87 & \pm 6.29 & 0.15 \\
\hline $\mathrm{Cr}$ & 0.94 & \pm 0.65 & 0.84 & \pm 0.24 & 0.94 & \pm 0.56 & 1.05 & \pm 0.90 & 0.001 \\
\hline$E F$ & 64.22 & \pm 5.93 & 63.88 & \pm 5.38 & 64.26 & \pm 5.71 & 64.74 & \pm 6.98 & 0.32 \\
\hline IVS & 10.84 & \pm 4.72 & 9.73 & \pm 1.68 & 10.78 & \pm 1.85 & 11.65 & \pm 2.50 & $<0.001$ \\
\hline Mass & 89.27 & \pm 25.34 & 79.87 & \pm 19.51 & 89.07 & \pm 21.89 & 100.81 & \pm 32.80 & $<0.001$ \\
\hline LVEDD & 44.91 & \pm 5.30 & 45.15 & \pm 4.92 & 44.82 & \pm 5.20 & 44.67 & \pm 5.92 & 0.61 \\
\hline LA Vol & 30.35 & \pm 10.62 & 25.83 & \pm 7.25 & 30.12 & \pm 10.01 & 36.23 & \pm 10.49 & $<0.001$ \\
\hline$E / A$ & 1.13 & \pm 0.48 & 1.33 & \pm 0.56 & 1.07 & \pm 0.41 & 1.07 & \pm 0.46 & $<0.001$ \\
\hline DT & 213.77 & \pm 53.54 & 205 & \pm 47.60 & 214.14 & \pm 49.85 & 226.84 & \pm 68.07 & $<0.001$ \\
\hline$e^{\prime}$ & 0.08 & \pm 0.05 & 0.11 & \pm 0.03 & 0.08 & \pm 0.05 & 0.06 & \pm 0.06 & $<0.001$ \\
\hline E/e' & 11.34 & \pm 5.55 & 6.51 & \pm 0.98 & 10.6 & \pm 1.78 & 20.19 & \pm 6.36 & $<0.001$ \\
\hline RVSP & 31.89 & \pm 9.70 & 28.32 & \pm 8.60 & 31.63 & \pm 8.36 & 36.5 & \pm 12.00 & $<0.001$ \\
\hline
\end{tabular}

A, late mitral diastolic flow velocity; BMI, body mass index; CAD, coronary artery disease; DM, diabetes mellitus; DT, deceleration time of mitral E wave; E, early mitral diastolic flow velocity; e', early diastolic mitral annular velocity, EF, ejection fraction; HTN, hypertension, IVS, interventricular septum; n, sample size, LA, left atrium; LAVI, left atrial volume index; LV, left ventricular; LVEDD, left ventricular end diastolic dimension; RVSP, right ventricular systolic pressure.

affect diastolic dysfunction status as compared with lower Vit D level (table 2). Predominalty female-elderly patients with Vit D sufficiency group who were on Vit D replacement therpay could have had a diagnosis of osteoporesis but we were not able to ascertain that because of retrospective design and limited data availability. It is very common in the USA for patients to be on over the counter Vit D supplement therapy for preventive measures without having a diagnosis of osteoporesis. One might argue that Doppler diastolic parameters of LV diastolic dysfunction are subject to acute hemodynamic changes. However, LAVI has been shown to be an excellent surrogate marker of long-term diastolic function, and correlates better as a sensitive parameter for diastology. ${ }^{16}$ LAVI did not show any association with Vit D levels by linear regression. A prior study looking at the relationship between Vit D status and LV geometry in a healthy population found a positive correlation between LV thickness and LVMI. ${ }^{17}$ In the present study, we found a significant relationship between Vit D level and interventricular septum and LVMI after adjusting for age, hypertension and Vit D therapy status suggesting the role of Vit D level on ventricular remodelling. Whether this is due to random chance or the first manifestation of Vit D deficiency is uncertain since no other echocardiographic parameter was different.

There are several possible explanations for the lack of a relationship between Vit D levels and diastolic dysfunction. The most important is the nature of a crosssectional study. These were unselected patients who happen to have a Vit D level obtained in close proximity to a diagnostic echocardiogram. There is insufficient information to assess the duration of Vit D deficiency, although it is known that a Vit D level usually represents a duration of at least several weeks. ${ }^{1}$ To cause diastolic impairment, this deficiency may need to be of a much longer duration. However, the Hoorn study examining serum Vit D level and LAVI after 8 years of follow-up failed to demonstrate any association between Vit D deficiency and diastolic dysfunction. ${ }^{14}$ They also used the product of LAV index and LVMI as a diastolic parameter, which is not part of the European and the American Society of Echocardiography recommendations of LV 
diastolic function. ${ }^{11}{ }^{12}$ However, our results, performed with additional diastolic parameter measurements, also confirm this prior study in terms of LAVI.

We believe that the strength of our study is the large sample size representing patients across a broad age spectrum, and the proximity of the echocardiogram with the Vit D level. One may argue that in our cohort, we did not look into difference in BNP, which could have supported our data in terms of LV filling pressures. Since the fundamental measurements of diastolic dysfunction are mitral inflow velocities and tissue Doppler imaging which were not different between Vit D deficiency and normal Vit D levels, the addition of BNP data would probably have had limited or no additional value. An additional strength of our study is that comprehensive echocardiography including detailed parameters of diastolic function was performed by a single core echocardiogram laboratory certified by the American Society of Echocardiography with echocardiography boarded certified cardiologists.

\section{Conclusion}

Despite growing medical literature suggesting Vit D deficiency is associated with cardiovascular disease, in this present study involving a large number of unselected patients, Vit D deficiency is not associated with LV diastolic dysfunction and an abnormal LAV index. There is a large ongoing prospective study with Vit D therapy which would help clarify the apparent relationship in the medical literature. ${ }^{18}$

Contributors HL conceived, designed, participated in data abstraction, analysis, interpretation and drafting of the manuscript. AP, FM, HC, AT, SC, SB and AAP analysed, interpreted data and provided intellectual content and approved the final manuscript. All authors approved the final manuscript.

Funding This research received no specific grant from any funding agency in the public, commercial or not-for-profit sectors.

Competing interests None.

Provenance and peer review Not commissioned; externally peer reviewed.

Data sharing statement No additional data are available.

Open Access This is an Open Access article distributed in accordance with the Creative Commons Attribution Non Commercial (CC BY-NC 3.0) license, which permits others to distribute, remix, adapt, build upon this work noncommercially, and license their derivative works on different terms, provided the original work is properly cited and the use is non-commercial. See: http:// creativecommons.org/licenses/by-nc/3.0/

\section{REFERENCES}

1. Lee $\mathrm{JH}$, O'Keefe $\mathrm{JH}$, Bell $\mathrm{D}$, et al. Vitamin D deficiency an important, common, and easily treatable cardiovascular risk factor? J Am Coll of Cardiol 2008;52:1949-56.

2. Wang L, Song Y, Manson JE, et al. Circulating 25-hydroxy-vitamin $\mathrm{D}$ and risk of cardiovascular disease: a meta-analysis of prospective studies. Circ Cardiovasc Qual Outcomes 2012;5: 819-29.

3. Gupta GK, Agrawal T, DelCore MG, et al. Vitamin D deficiency induces cardiac hypertrophy and inflammation in epicardial adipose tissue in hypercholesterolemic swine. Exp Mol Pathol 2012;93:82-90.

4. Wang TJ, Pencina MJ, Booth SL, et al. Vitamin D deficiency and risk of cardiovascular disease. Circulation 2008;117:503-11.

5. Chen S, Law CS, Grigsby CL, et al. Cardiomyocyte-specific deletion of the vitamin $D$ receptor gene results in cardiac hypertrophy. Circulation 2011;124:1838-47.

6. Morris HA, Anderson PH. Autocrine and paracrine actions of vitamin D. Clin Biochem Rev 2010;31:129-38.

7. Anderson JL, May HT, Horne BD, et al. Relation of vitamin D deficiency to cardiovascular risk factors, disease status, and incident events in a general healthcare population. Am J Cardiol 2010;106:963-8.

8. Stork T, Mockel M, Danne O, et al. Left ventricular hypertrophy and diastolic dysfunction: their relation to coronary heart disease. Cardiovasc Drugs Ther 1995;9(Suppl 3):533-7.

9. Mockel M, Stork T. Diastolic function in various forms of left ventricular hypertrophy: contribution of active Doppler stress echo. Int J Sports Med 1996;17(Suppl 3):S184-90.

10. Ross AC, Manson JE, Abrams SA, et al. The 2011 report on dietary reference intakes for calcium and vitamin $D$ from the Institute of Medicine: what clinicians need to know. J Clin Endocrinol Metab 2011;96:53-8.

11. Nagueh SF, Appleton CP, Gillebert TC, et al. Recommendations for the evaluation of left ventricular diastolic function by echocardiography. Eur J Echocardiogr 2009;10:165-93.

12. Nagueh SF, Appleton CP, Gillebert TC, et al. Recommendations for the evaluation of left ventricular diastolic function by echocardiography. J Am Soc Echocardiogr 2009;22:107-33.

13. Tamez $\mathrm{H}$, Zoccali $\mathrm{C}$, Packham $\mathrm{D}$, et al. Vitamin $\mathrm{D}$ reduces left atrial volume in patients with left ventricular hypertrophy and chronic kidney disease. Am Heart J 2012;164:902-9.

14. van Ballegooijen AJ, Snijder MB, Visser $M$, et al. Vitamin D in relation to myocardial structure and function after eight years of follow-up: the Hoorn study. Ann Nutr Metab 2012;60: 69-77.

15. Ernande L, Bergerot C, Rietzschel ER, et al. Diastolic dysfunction in patients with type 2 diabetes mellitus: is it really the first marker of diabetic cardiomyopathy? J Am Soc Echocardiog 2011;24: 1268-75 e1

16. Tsang TS, Barnes ME, Gersh BJ, et al. Left atrial volume as a morphophysiologic expression of left ventricular diastolic dysfunction and relation to cardiovascular risk burden. Am J Cardiol 2002;90:1284-9.

17. Ameri $\mathrm{P}$, Canepa $\mathrm{M}$, Milaneschi $\mathrm{Y}$, et al. Relationship between vitamin $D$ status and left ventricular geometry in a healthy population: results from the Baltimore Longitudinal Study of Aging. J Inter Med 2013;273:253-62.

18. Manson JE, Bassuk SS, Lee IM, et al. The VITamin D and OmegA-3 TriaL (VITAL): rationale and design of a large randomized controlled trial of vitamin D and marine omega-3 fatty acid supplements for the primary prevention of cancer and cardiovascular disease. Contemp Clinical Trials 2012;33:159-71. 